\title{
The Relationship between Periodontitis and Oral Health Literacy among the Older People in Thailand
}

\author{
Panat Piyakhunakorn ${ }^{1,2,3}$ \& Nithimar Sermsuti-anuwat ${ }^{3}$ \\ ${ }^{1}$ Master of Science Program in Geriatric Dentistry and Special Patients Care (International Program), Faculty of \\ Dentistry, Chulalongkorn University, Wangmai, Pathumwan, Bangkok, Thailand \\ ${ }^{2}$ Panare Hospital, Dental Public Health Division, Tha Kham, Panare District, Pattani, Thailand \\ ${ }^{3}$ Faculty of Dentistry, Chulalongkorn University, Wangmai, Pathumwan, Bangkok, Thailand \\ Correspondence: Nithimar sermsuti-anuwat, Faculty of Dentistry, Chulalongkorn University, 34 Henri-Dunant \\ Road, Wangmai, Pathumwan, Bangkok, 10330, Thailand. Tel: 66-218-9016.
}

Received: January 23, 2021 Accepted: April 28, 2021 Online Published: May 14, 2021

doi:10.5539/gjhs.v13n6p103 URL: https://doi.org/10.5539/gjhs.v13n6p103

\begin{abstract}
Objective: The purpose of this study was to evaluate the relationship between periodontitis and oral health literacy among the older population in Thailand.

Material and Methods: This cross-sectional study was performed between July 1 and September 30, 2020, in Panare district, Pattani province, Thailand. The inclusion criteria were older individuals more than 60 years of age who had at least six remaining teeth. Information on sociodemographic characteristics and oral health-related behaviors were collected using a self-reported questionnaire. Oral health literacy was categorized using the Thai version of the Health Literacy in Dentistry scale (HeLD-Th). A trained examiner performed clinical periodontal examinations. The data were analyzed using the Mann-Whitney U test, Fisher's exact test, and binary logistic regression analysis.

Results: A total of 216 independently living older adults participated and completed the study protocol. The initial analyses indicated significant associations between severe periodontitis and low oral health literacy $(p=0.029)$ and insufficient toothbrushing duration $(\mathrm{p}<0.001)$. However, in multivariate analysis, only toothbrushing duration showed significant association $(\mathrm{p}=0.003)$.
\end{abstract}

Conclusions: Oral health literacy interventions and oral hygiene practices for improving periodontal health status among the Thai older adults are necessary.

Keywords: periodontal health, periodontitis, oral health literacy, geriatrics, oral health

\section{Introduction}

Most Thai older adults experience oral diseases such as dental caries and periodontitis. The prevalence of periodontitis in Thai individuals aged $60-74$ years is $36.3 \%$, and $12.2 \%$ have severe periodontitis. Consequently, $77.6 \%$ of the Thai elderly population experience tooth loss (Ministry of Public Health [MOPH], 2017). Periodontitis is a bacterial infectious disease with loss of tooth supportive tissue and alveolar bone secondary to inflammation. Advanced and severe periodontitis induces tooth mobility and loss and compromises the quality of life (Chapple et al., 2018). Furthermore, periodontitis has been related to the prevalence of chronic diseases (Özçaka, Becerik, Bıçakcı, \& Kiyak, 2014), such as pneumonia (Müller, 2015), diabetes, osteoporosis, and cardiovascular diseases (Kuo, Polson, \& Kang, 2008).

Ship and Craw (1994) clarified that periodontitis is caused by insufficient oral hygiene maintenance. Older individuals have limitations in the following personal factors that interfere with adequate oral hygiene maintenance: (1) Reduction in muscular coordination of the mucosa, lips, and tongue. (2) Systemic diseases such as Alzheimer's disease, dementia, and Parkinson's disease affect the ability to maintain oral hygiene. (3) Various medications commonly prescribed to older individuals lead to diminished salivary output exerting a harmful effect on the periodontal tissues. (4) Irregular dental visits: older individuals who do not schedule regular oral health checkups tend to have a greater risk of periodontal disease.

Oral health literacy $(\mathrm{OHL})$ is the ability to receive, process, and understand the necessary information and 
resources available for oral health to make appropriate health decisions (National Institute of Dental and Craniofacial Research, 2005). Inadequate OHL among adults can significantly influence the oral health status (Kickbusch, Pelikan, Apfel, \& Tsouros, 2013). Limited OHL leads to periodontal disease in adults (Batista, Lawrence, \& Rosario de Sousa, 2018; Baskaradoss, 2018; Mohammadi, Malekmohammadi, Hajizamani, \& Mahani, 2018). Lower OHL is related to severe periodontal disease (Wehmeyer, Corwin, Guthmiller, \& Lee, 2014). Development of oral health in the older population requires the implementation of effective oral health education programs (Petersen \& Yamamoto, 2005). Therefore, adequate OHL interventions for older individuals are an important public health requirement.

In Thailand, studies that have assessed the OHL in the older community are scarce. To the best of our knowledge, the relationship between OHL and periodontal disease among the Thai older population has not been determined. We hypothesized that low OHL is associated with severe periodontitis. The findings of this study will be useful for planning improvements in OHL interventions among the older population in Thailand. Hence, this study aimed to investigate the relationship between periodontal disease and OHL among the older population in the Panare district, Pattani province, Thailand.

\section{Method}

\subsection{Study Design and Location}

This cross-sectional study was conducted between July 1 and September 30, 2020, in the Panare district, Pattani province, Thailand.

\subsection{Ethical Approval of Research}

The research protocol was approved by the Research Ethics Committee of Chulalongkorn University, Thailand (COA No 058/2020). This study was performed in accordance with the Helsinki Declaration. Each participant signed written informed before participation.

\subsection{Participant Selection}

The sample size was estimated using parameters from a previous study (Sermsuti-Anuwat \& Pongpanich, 2019). This study required 216 participants, assuming a two-sided test with a significance level of less than 0.05 . Interested older individuals were invited to enroll in the study. We included independent living men and women over 60 years of age, with at least six remaining teeth, and excluded older adults with a severe chronic illnesses or communication problems or disabilities such as visual impairment, hearing loss, or mental conditions.

\subsection{Data Collection}

One examiner (a periodontist) collected all the clinical data between July 1 and September 30, 2020. Intra-oral examinations were performed at the district health promoting hospitals located in the Panare district. A pilot study was performed for calibration; 30 voluntary older residents from a nearby community participated in the pilot study. The kappa inter-examiner coefficient showed 90\% (excellent) reliability (Petersen, Baez, \& World Health Organization, 2013).

A calibrated examiner performed the periodontal examination. The oral examination procedures and diagnostic criteria followed the 8th Thailand National Oral Health Survey performed in 2017 (MOPH, 2017). The periodontal status was examined using the WHO Community Periodontal Index probe, which is specially designed for this purpose and is light in weight. The pocket depths were recorded and classified as follows: pocket depths $<6 \mathrm{~mm}$ indicated mild-to-moderate periodontitis and pocket depths $\geq 6 \mathrm{~mm}$ indicated severe periodontitis (MOPH, 2017). Demographic and socioeconomic data and oral health-related behaviors were assessed using a self-reported questionnaire by trained interviewers.

The instrument used to evaluate OHL levels was the Health Literacy in Dentistry scale (HeLD-Th). It has total scores from 0 to 56; a higher HeLD-Th score is interpreted as a higher OHL level. The HeLD-Th has been shown to exhibit sufficient psychometric properties. Content validity testing by an expert panel showed acceptable item-objective congruence index value of $0.76(\mathrm{MOPH}, 2017)$. A pilot study was performed for reliability testing with an overall Cronbach's alpha of 0.946 .

\subsection{Statistics and Data Analysis}

Data were analyzed using the SPSS software (IBM SPSS Statistics for Windows, Version 22.0. Armonk, NY: IBM Corp., USA). The Shapiro-Wilk test was used for normality testing; all continuous variables were non-normally distributed. The Mann-Whitney U test was used for comparing the HeLD-Th scores among participants. The Fisher's exact test was used to analyze the relationship between OHL and related variables including age $(\leq 74$ 
years/> 74 years); sex (Female/Male); education ( $\leq$ primary school/>primary school); history of diabetes mellitus (Yes/No); history of cardiovascular disease (Yes/No); frequency of toothbrushing ( $\geq$ twice a day $/<$ twice a day); duration of toothbrushing ( $\geq 2$ minutes $/<2$ minutes); and regular dental care (Yes/No). Binary logistic regression analysis was performed to investigate the associations among OHL, related variables, and periodontitis.

\section{Results}

Table 1 shows the data of 216 community dwelling older adults aged 60-94 years (mean 69.91 years); all participants were living independently. The median HeLD-Th score was 39. A high OHL was observed among $50.5 \%$ of the study participants; most were women $(69.9 \%)$ with age $\leq 74$ years $(75 \%)$, education $<$ primary school (70.4\%), and without history of diabetes mellitus or cardiovascular disease. Regarding routine oral hygiene habits, most participants reported sufficient toothbrushing frequency $(76.0 \%)$ and adequate toothbrushing duration (64.8\%). Although all participants had minimum dental benefits from the Universal Healthcare Coverage scheme, most did not schedule any dental visit in the past 12 months (90.4\%). For periodontal disease, nearly $60 \%$ of the study participants had mild-to-moderate periodontitis.

As shown in Table 2, the median HeLD-Th score was 39, participants with HeLD-Th scores $<39$ were considered to have low OHL, and those with HeLD-Th scores $\geq 39$ were considered to have high OHL. Fisher's exact tests found statistically significant relationships of periodontitis with OHL $(p=0.039)$, the same as periodontitis and toothbrushing duration $(p=0.001)$. Furthermore, the associations of periodontitis with $\operatorname{sex}(p=0.133)$, education $(p=0.130)$, and diabetes mellitus $(p=0.135)$ presented $p<0.25$; hence, they were included in the binary logistic regression analyses.

Table 3 displays the results of the logistic regression analyses; initial analyses indicated statistically significant associations between severe periodontitis and low OHL $(p=0.029)$ and inadequate toothbrushing duration of fewer than 2 minutes $(\mathrm{p}<0.001)$. However, the final model included only insufficient toothbrushing duration and showed that participants with toothbrushing duration of fewer than 2 minutes were approximately 2.5 times more likely to have severe periodontitis than those with adequate toothbrushing duration (Odds ratio $=2.508, p=0.003$ ).

Table 1. Baseline demographic and overall characteristics of the study participants $(\mathrm{N}=216)$

\begin{tabular}{lcc}
\hline Continuous variables & Mean \pm Standard deviation & Median (Range) \\
\hline Oral health literacy & $38.04 \pm 10.477$ & $39(5-56)$ \\
Age (years) & $69.91 \pm 6.392$ & $69(60-94)$ \\
\hline Categorical variables & Number & $\mathbf{\%}$ \\
\hline Oral health literacy levels: & 109 & 50.5 \\
High $(\geq 39)$ & 107 & 49.5 \\
Low $(<39)$ & & \\
\hline Age: & 162 & 75 \\
Age $\leq 74$ years & 54 & 25 \\
Age $>74$ years & 151 & 69.9 \\
\hline Sex: & 65 & 30.1 \\
Female & & \\
Male & 64 & 29.6 \\
\hline Education: & 152 & 70.4 \\
$>$ Primary education & & 84.3 \\
$\leq$ Primary education & 182 & 15.7 \\
\hline Diabetes mellitus: & 34 & \\
No & & \\
Yes & &
\end{tabular}




\section{Cardiovascular disease:}

$\begin{array}{lcc}\text { No } & 205 & 94.9 \\ \text { Yes } & 11 & 5.1\end{array}$

\section{Toothbrushing frequency:}
$\geq$ twice a day
171
79.2
$<$ twice a day
45
20.8

\section{Toothbrushing duration:}
$\geq 2$ minutes
148
68.5
$<2$ minutes
68
31.5

\section{Regular dental care:}

$\begin{array}{lcr}\text { Yes } & 25 & 11.6 \\ \text { No } & 191 & 88.4\end{array}$

\section{Periodontitis}

Mild-to-Moderate

127

58.8

Severe

Universal Healthcare Coverage:

Table 2. Factors associated with periodontal disease in the study participants $(\mathrm{N}=216)$

\begin{tabular}{|c|c|c|c|}
\hline \multirow{2}{*}{ Variables } & \multicolumn{2}{|c|}{ Periodontitis $^{\text {a }}$} & \multirow{2}{*}{ p-value ${ }^{b}$} \\
\hline & Mild-to-moderate & Severe & \\
\hline Total & $127(58.8)$ & $89(41.2)$ & \\
\hline Oral Health Literacy levels & & & 0.038 \\
\hline High $(\geq 39)$ & $72(66.1)$ & $37(33.9)$ & \\
\hline Low $(<39)$ & $55(51.4)$ & $52(48.6)$ & \\
\hline Age: & & & 0.751 \\
\hline Age $\leq 74$ years & $94(58.0)$ & $68(42.0)$ & \\
\hline Age $>74$ years & $33(61.1)$ & $21(38.9)$ & \\
\hline Sex: & & & 0.133 \\
\hline Female & $94(62.3)$ & $57(37.7)$ & \\
\hline Male & $33(50.8)$ & $32(49.2)$ & \\
\hline Education: & & & 0.130 \\
\hline$>$ Primary education & $43(67.2)$ & $21(32.8)$ & \\
\hline$\leq$ Primary education & $84(55.3)$ & $68(44.7)$ & \\
\hline Diabetes mellitus: & & & 0.135 \\
\hline No & $111(61.0)$ & $71(39.0)$ & \\
\hline Yes & $16(47.1)$ & $18(52.9)$ & \\
\hline Cardiovascular disease: & & & 0.764 \\
\hline No & $121(59.0)$ & $84(41.0)$ & \\
\hline Yes & $6(54.5)$ & $5(45.5)$ & \\
\hline
\end{tabular}




\begin{tabular}{|c|c|c|c|}
\hline Toothbrushing frequency: & & & 0.496 \\
\hline$\geq$ twice a day & $103(60.2)$ & $68(39.8)$ & \\
\hline$<$ twice a day & $24(53.3)$ & $21(46.7)$ & \\
\hline Toothbrushing duration: & & & 0.001 \\
\hline$\geq 2$ minutes & $99(66.9)$ & $49(33.1)$ & \\
\hline$<2$ minutes & $28(41.2)$ & $40(58.8)$ & \\
\hline Regular dental care: & & & 0.830 \\
\hline Yes & $14(56.0)$ & $11(44.0)$ & \\
\hline No & $113(59.2)$ & $78(40.8)$ & \\
\hline
\end{tabular}

Notes. ${ }^{\mathrm{a}}$ Number (\%).

${ }^{\mathrm{b}}$ Statistical calculation by Fisher's exact test.

Table 3. Simple bivariate and multivariate binary logistic regression analyses for periodontal disease in the participants $(\mathrm{N}=216)$

\begin{tabular}{|c|c|c|c|c|}
\hline \multirow[b]{2}{*}{ Variables } & \multicolumn{4}{|c|}{ Periodontitis } \\
\hline & $\begin{array}{l}\text { Unadjusted } \\
\text { OR (95\% CI) }\end{array}$ & p-value ${ }^{a}$ & $\begin{array}{l}\text { Adjusted } \\
\text { OR }(95 \% \mathrm{CI})\end{array}$ & p-value ${ }^{b}$ \\
\hline $\begin{array}{l}\text { Oral Health Literacy } \\
\text { levels: }\end{array}$ & & 0.029 & & 0.201 \\
\hline High ( $\geq 39)$ & 1 & & 1 & \\
\hline Low $(<39)$ & $1.840(1.063-3.184)$ & & $1.470(0.814-2.655)$ & \\
\hline Sex: & & 0.117 & & 0.137 \\
\hline Female & 1 & & 1 & \\
\hline Male & $1.599(0.889-2.877)$ & & $1.599(0.861-2.969)$ & \\
\hline Education: & & 0.106 & & 0.261 \\
\hline$>$ Primary education & 1 & & 1 & \\
\hline$\leq$ Primary education & $1.658(0.899-3.057)$ & & $1.452(0.758-2.783)$ & \\
\hline Diabetes mellitus: & & 0.133 & & 0.184 \\
\hline No & 1 & & 1 & \\
\hline Yes & $1.759(0.842-3.673)$ & & $1.685(0.780-3.641)$ & \\
\hline Toothbrushing duration: & & $<0.001$ & & 0.003 \\
\hline$\geq 2$ minutes & 1 & & 1 & \\
\hline$<2$ minutes & $2.886(1.597-5.217)$ & & $2.508(1.360-4.625)$ & \\
\hline
\end{tabular}

Notes. ${ }^{\text {a }}$ p-value as per univariate binary logistic regression.

${ }^{\mathrm{b}} \mathrm{p}$-value as per multivariate binary logistic regression.

Abbreviations: $\mathrm{OR}=$ Odds Ratio; $\mathrm{CI}=$ Confidence Interval.

\section{Discussion}

The study findings show the relationship between periodontitis and OHL among the older population in Thailand. The study participants generally performed daily living activities independently; $70.4 \%$ of participants had primary education, which was slightly lower than the national report, which stated that $71.8 \%$ older individuals had been to a primary school (MOPH, 2017). Regarding periodontal disease, $42.1 \%$ of the participants had severe periodontitis, which is nearly 3.5 -folds higher than the national average (12.2\%) (MOPH, 2017). 
The HeLD-Th instrument (Sermsuti-Anuwat \& Pongpanich, 2019) revealed that participants with severe periodontitis were more likely to have lower OHL. This finding is consistent with a previous study that showed the relationship between lower OHL and more severe periodontal disease (Wehmeyer et al., 2014).

Significant relationships of periodontitis with OHL and toothbrushing duration were observed; a result similar to that of previous studies (Matsui et al., 2017; Wehmeyer et al., 2014). Additionally, a statistical association with $\mathrm{p}<$ 0.25 of periodontal disease with sex, education, and diabetes mellitus was observed. These findings are consistent with a study from Thailand, which concluded that sex, age, education, diabetes mellitus, and oral hygiene status are significantly related to periodontal disease severity in Thai adults (Torrungruang et al., 2005).

The binary logistic regression models were used to assess the relationship between periodontitis and potential risk factors. OHL and toothbrushing duration were significantly associated with severe periodontitis in the unadjusted model. The same independent variables were then analyzed using multivariate regression; only toothbrushing duration was significantly associated with severe periodontitis in the final model. This finding is concordant with those of Matsui et al. (2017), who suggested that low toothbrushing frequency and short toothbrushing duration are related to periodontal disease and endothelial dysfunction.

We could possibly accept the hypothesis of this study that low OHL is associated with severe periodontitis. However, this cross-sectional study has a few limitations; all data were collected using self-reported questionnaires with a small sample size. Therefore, the generalization of the findings of this study is questionable. Future studies should involve a more extensive study population.

The HeLD-Th scores indicated that participants with severe periodontitis were associated with lower OHL. Consequently, dental professionals should consider and strive to address these potential OHL factors among the Thai older population. Moreover, adequate OHL interventions can positively influence better oral health behaviors and improve the oral health status of the Thai older population.

\section{Acknowledgments}

This Research is funded by Chulalongkorn University (Ratchadaphiseksomphot Endowment Fund) CU_GR_63_12_32_05.

\section{Competing Interests Statement}

No conflicts of interest have been declared.

\section{References}

Baskaradoss, J. K. (2018). Relationship between oral health literacy and oral health status. BMC Oral Health, 18, 172. https://doi.org/10.1186/s12903-018-0640-1

Batista, M. J., Lawrence, H. P., \& Rosario de Sousa, M. L. (2018). Oral health literacy and oral health outcomes in an adult population in Brazil. BMC Public Health, 18, 60. https://doi.org/10.1186/s12889-017-4443-0

Chapple, I. L. C., Mealey, B. L., Van Dyke, T. E., Bartold, P. M., Dommisch, H., Eickholz, P., .. Yoshie, H. (2018). Periodontal health and gingival diseases and conditions on an intact and a reduced periodontium: Consensus report of workgroup 1 of the 2017 World Workshop on the Classification of Periodontal and Peri-Implant $\begin{array}{lllll}\text { Diseases and Conditions. Journal of Clinical Periodontology, 45, S68-S77. } & \text {. }\end{array}$ https://doi.org/10.1111/jcpe.12940

Hjertstedt, J., Barnes, S. L., \& Sjostedt, J. M. (2014). Investigating the impact of a community-based geriatric dentistry rotation on oral health literacy and oral hygiene of older adults. Gerodontology, 31(4), 296-307. https://doi.org/10.1111/ger.12038

Kickbusch, I., Pelikan, J. M., Apfel, F., \& Tsouros, A. D. (2013). Health literacy. The solid facts. Copenhagen, Denmark: WHO Regional Office for Europe.

Kuo, L.-C., Polson, A. M., \& Kang, T. (2008). Associations between periodontal diseases and systemic diseases: a review of the inter-relationships and interactions with diabetes, respiratory diseases, cardiovascular diseases and osteoporosis. Public health, 122(4), 417-433. https://doi.org/10.1016/j.puhe.2007.07.004

Matsui, S., Kajikawa, M., Maruhashi, T., Iwamoto, Y., Iwamoto, A., Oda, N., ... Higashi, Y. (2017). Decreased frequency and duration of tooth brushing is a risk factor for endothelial dysfunction. International Journal of Cardiology, 241, 30-34. https://doi.org/10.1016/j.ijcard.2017.03.049

Mohammadi, T. M., Malekmohammadi, M., Hajizamani, H. R., \& Mahani, S. A. (2018). Oral health literacy and its determinants among adults in Southeast Iran. European Journal of Dentistry, 12(03), 439-442. 
https://doi.org/10.4103/ejd.ejd_429_17

Ministry of Public Health. (2017). National Oral Health Survey of Thailand (2017) Report. Thailand: Ministry of Public Health.

Müller, F. (2015). Oral hygiene reduces the mortality from aspiration pneumonia in frail elders. Journal of Dental Research, 94(3_suppl), 14S-16S. https://doi.org/10.1177/0022034514552494

National Institute of Dental and Craniofacial Research, National Institute of Health, U.S. Public Health Service, Department of Health and Human Services. (2005). The invisible barrier: literacy and its relationship with oral health. A report of a workgroup sponsored by the National Institute of Dental and Craniofacial Research (NIDCR), National Institute of Health, U.S. Public Health Service, Department of Health and Human $\begin{array}{lllll}\text { Services. Journal of Public Health Dentistry, 65(3), 174-182. } & \text {. }\end{array}$ https://doi.org/10.1111/j.1752-7325.2005.tb02808.x

Özçaka, Ö., Becerik, S., Bıçakcı, N., \& Kiyak, A. H. (2014). Periodontal disease and systemic diseases in an older population. Archives of Gerontology and Geriatrics, 59(2), 474-479. https://doi.org/10.1016/j.archger.2014.05.011

Petersen, P. E., \& Yamamoto, T. (2005). Improving the oral health of older people: the approach of the WHO Global Oral Health Programme. Community Dentistry and Oral Epidemiology, 33(2), 81-92. https://doi.org/10.1111/j.1600-0528.2004.00219.x

Petersen, P. E., Baez, R. J., \& World Health Organization. (2013). Oral health surveys: basic methods (5th ed.). World Health Organization.

Sermsuti-Anuwat, N., \& Pongpanich, S. (2019). Validation of Thai version of the Health Literacy in Dentistry scale: Validation among Thai adults with physical disabilities. Journal of Investigative and Clinical Dentistry, 10(4), e12474. https://doi.org/10.1111/jicd.12474

Ship, J. A., \& Crow, H. C. (1994). Diseases of periodontal tissues in the elderly. Description, epidemiology, aetiology and drug therapy. Drugs \& Aging, 5(5), 346-357. https://doi.org/10.2165/00002512-199405050-00004

Tenani, C. F., De Checchi, M. H. R., Bado, F. M. R., Ju, X., Jamieson, L., \& Mialhe, F. L. (2020). Influence of oral health literacy on dissatisfaction with oral health among older people. Gerodontology, 37(1), 46-52. https://doi.org/10.1111/ger.12443

Torrungruang, K., Tamsailom, S., Rojanasomsith, K., Sutdhibhisal, S., Nisapakultorn, K., Vanichjakvong, O., ... \& Sritara, P. (2005). Risk indicators of periodontal disease in older Thai adults. Journal of Periodontology, 76(4), 558-565. https://doi.org/10.1902/jop.2005.76.4.558

Wehmeyer, M. M., Corwin, C. L., Guthmiller, J. M., \& Lee, J. Y. (2014). The impact of oral health literacy on periodontal health status. Journal of Public Health Dentistry, 74(1), 80-87. https://doi.org/10.1111/j.1752-7325.2012.00375.x

\section{Copyrights}

Copyright for this article is retained by the author(s), with first publication rights granted to the journal.

This is an open-access article distributed under the terms and conditions of the Creative Commons Attribution license (http://creativecommons.org/licenses/by/4.0/). 